\title{
أثر استفدام التدريب بالأسلوب المتباين على تحسين المستوى المهارى للاعبي كرة القدم بدولة الكويت
}

د/ أحمد إبراهيم عويد المطيري

أن التدريب الرياضى يرتبط بنظريات و أسس العلوم الأخرى و التى تعتمد عليها فى تثكيل معارفه

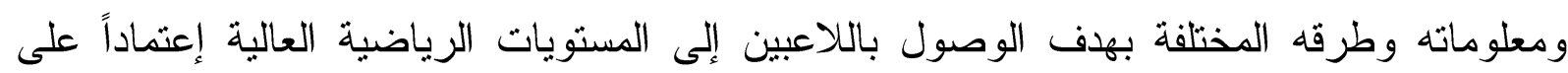
الأسلوب العلمى، ومن منطلق هذا يتم إعداد اللاعبين من جميع الجوانب البدنية والمهارية والخططية

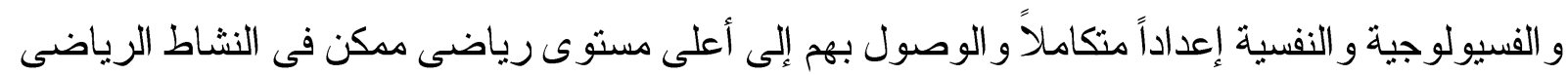

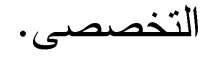
ويوضح حسين العلي وعامر شغاتي ( • + ·rم) أن التدريب الرياضي المنظم هو وسيلة للوصول إلى المستويات العالية وتحقيق الأرقام القياسية إذا ما نوفرت الظروف الأخرى من الاستعدادات و القدرات و القابليات و الإمكانيات المختلفة، فطر ائق التدريب هي الوسيلة الرئيسية و الأساسية المستخدمة في عملية التأثير في المستوى البدني و المهاري و الوظيفي للرياضي.(ب: (1) ويذكر عصام عبد الحميا ( ... rم) أن كل متابع لنطور المستويات الرياضية في العالم يدرك أن للتدريب الرياضي شأن عظيم في إعداد وصياغة و 'تطوير القدرات الإنسانية بأبعادها المختلفة من أجل تفجير أقصى ما يمكنه من قدرات وما بداخل الإنسان من طاقات في اتجاه الهدف المنشود. (7:

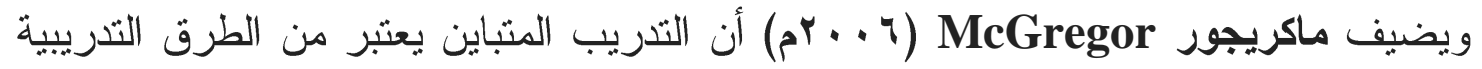
الحديثة في المجال الرياضي وأن العديد من الدراسات التي تتاولت تأثيرات التدريب المتباين على المتغير ات البدنية و الفسيولوجية على اللاعبين الناشئين و الكبار • (9: 1ـ)

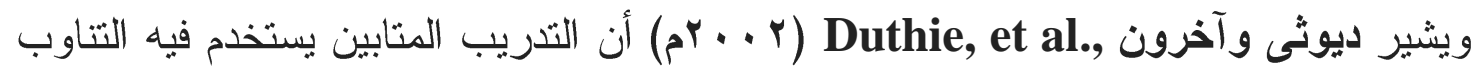

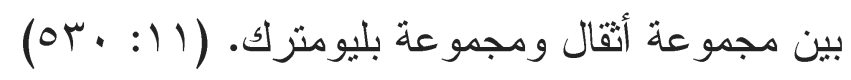
' حاصل على درجة الدكتوراه فى التربية البدنية ورئيس قسم تربية بدنية بوزارة التربية ـ دولة الكويت. 


\section{مشكنة البحث و أهميته:}

أن الطابع المميز للمهار ات الحركية الأساسية لنوع النشاط الرياضى التخصصى هو الذى يحدد

$$
\text { نوعية بر امج التدريب المستخدمة في تتمينها وتطويرها. }
$$

و تشير سندس الثيخلى وآخرون (1 (1 + rم) يعد الأسلوب المتباين من الاساليب التي تسترعي

انتباه المدربين لتحقيق استفادة قصوى من أداءء تمرين البليومنرك بعد أداء تدريب الأثقال الذي يماثله في المجموعات العضلية نفسها، إذا أن كل الو اجبات الحركية تتطلب انتاج القوة التي تاخذ انو اع منها

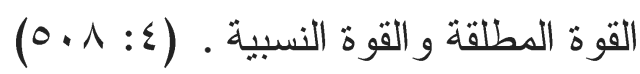

ويضيف حسين العلي وعامر شغاتي ( • ( • م) أن التدريب المتباين هو أسلوب تدريبي ثتم فيه محاولة الوصول إلى أقصى درجة من الفاعلية عن طريق استخدام القوة بأساليب منباينة ومتضادة في الاتجاه داخل الوحدة التدريبية الواحدة أو داخل المجموعات من التمرينات، كما أنه أحد الأساليب الني تخلق الإستجابات و التكيفات البدنية و الوظيفية التي تلعب دوراً فعالاً في تطوير الإنجاز الرياضى. (r:

وكما يؤكد سميليوث وآخرون .Smilios, et al (ه . ․ . م) على أن التذريب المتباين باستخدام الأحمال التي تتر اوح شدتها ما بين الخفيفة والمتوسطة، يكون له نأثير اً إيجابياً على القوة المميزة بالسرعة شريطة أن تؤدى تمرينات الأثقال قبل التدريب البليومتري في الوحدة التدريبية.

$(r): 10)$

ويفسر شيب سيجمون Chip Sigmon, (r ( . rم) أنه عند تطبيق التدريب المركب بأسلوب التباين في الثدات و الأحجام و الراحات و أسلوب التنفيذ، عندها نطلق على التدريب مصطلح التدريب المتباين حيث يتم التتاوب في الأداء بين مجموعات الأثقال و البليومترك. ( . (: 1؟) وكما يذكر كل من عبد العزيز النمر وناريمان الخطيب (ج9 9 ام) أنه على الرياضي ان يتدرب بشدة عالية لكل من تدريبات الأثقال وتدريبات البليومترك وهذا يعني ان الحجم يكون منخفضا بما فيه الكفاية وذلك لتجنب حدوث الاعيا ء، لذا يجب التزكيز على نوعية التمرينات المستخدمة عن طريق تشابه التمرينات المستخدمة في الأثقال مع التمرينات المستخدمة في 
تدريبات البليومترك في الأداء الحركى و العضدات المستخدمة في كل تمرين. (0: م • ب) وكما يوضح على البيك وآخرون (9 . . rم) أن اللاعب لا يستطيع الأداء الأمثل للمهارات الحركية الأساسية للنشاط الممارس ما لم يتمتع بالقدر ات البدنية الخاصة التي ينطلبها تتفيذ المهارة، وأن استخدام التمرينات التي تتشابه في تكوينها الحركي مع الحركات التي تؤدى أثناء المنافسة يعتبر بمثابة أعداد مباشر للاعب و إحدى وسائل تطوير حالة اللاعب التدريبية، وأن تكرار أداء المهارة في المو اقف المشابهة لمو اقف المبار اة تلعب دور رئيسي في تتمية القدرات البدنية الخاصة بهذه المهار ات. (V: 7 (Y) Duthie, et al., وتتضح أهمية البحث من خلال نتائج دراسة كلاً من ديوثى وأخرون

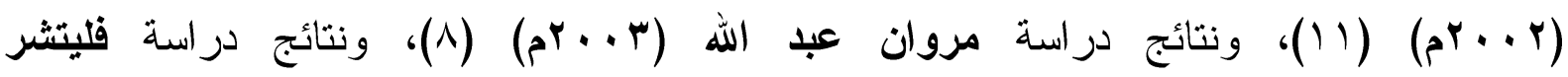
Smilios, وهارتويل Fletcher \& Hartwell (צ · · r م) (Y ())، ونتائج در اسة سميليوث وآخرون et al. المهارية للاعبين. هدف البحث:

يهدف البحث إلى در اسة أثز استخدام التدريب بالأسلوب المتباين على تحسين المستوى المهارى للاعبي كرة القدم بدولة الكويت. فروض الإث: - توجد فروق ذات دلالة إحصائية بين القياسين القبلى و البعدى للمجموعة التجريبية فى مستوى الأداء المهاري لصالح القياس البعدى لدى لاعبي كرة القدم. - مصطلحات البحث: يعرف بر اد ماكريجور Brad McGregor, (ד + . r م) التذريب المتباين بأنه شكل تدريبي يتم فيه التتاوب بين أداء مجموعة التدريب بالأثقال بشدة عالية يتبعها مباشرة أداء مجمو عة تمرينات بليومنرية بشدات متنوعة مع الوضع في الاعتبار أن تشتابه المجموعات العضلية العاملة و المسار الحركي للأداء لمجموعة تمرينات البليومتري مع مجموعة التذريب بالأثقال. (9: 0ب ا ) الار اسات المرجعية: 
أولاً: الاراسات المرجعية العربية:

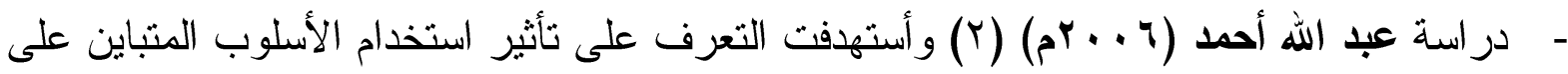
تعلم بعض المهارات الأساسية لكرة القدم لتلاميذ المرحلة الإعدادية، واستخدم الباحث المنهج

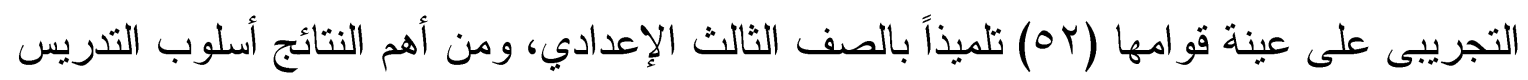
المنباين كان له تأثير إيجابي فعال أفضل من أسلوب الأو امر في تعلم بعض المهارات الأساسية لكرة القدم (قبد البحث).

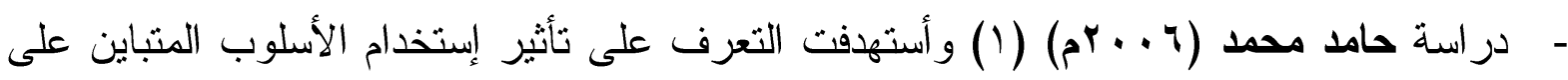

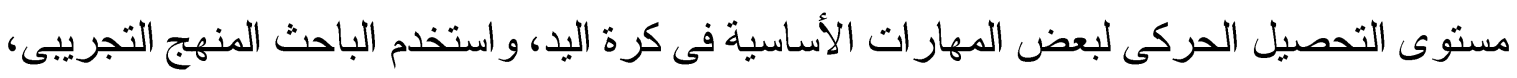
وتم إختيار عينة قو امها (َ؟) طالباً بالفرقة الثالثة بكلية التزبية الرياضية بالزقازيق، ومن أهم النتائج

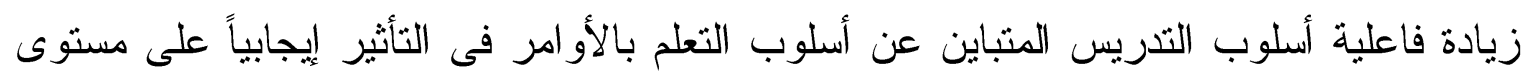
التحصيل الحركى للمهار ات الهجومية قيد البحث فى كرة اليد.

ثانياً: الار اسات المرجعية الأجنبية:

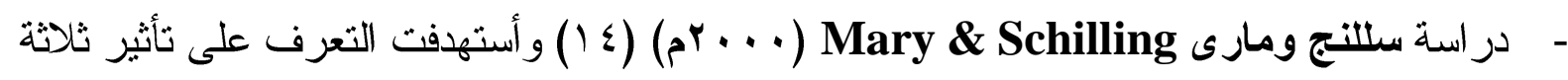
من أساليب التنريس علي الأداء الرياضي لطلبة الجامعات، واستخدم الباحثان المنهج التجريبي، على عينة قواها (·Pl) طالب، ومن أهم النتائج: أسلوبى (التعلم التبادلي - الواجبات الحركية) يؤديان إلي تحسين مستوى أداء مهارة التصويبة الكرباجية من الإرتكاز في كرة اليد مقارنة بأسلوب التعلم بالأو امر .

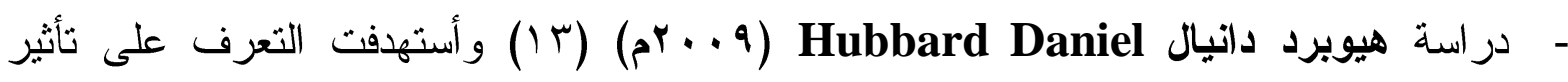

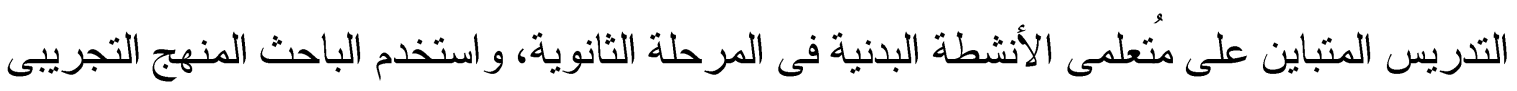

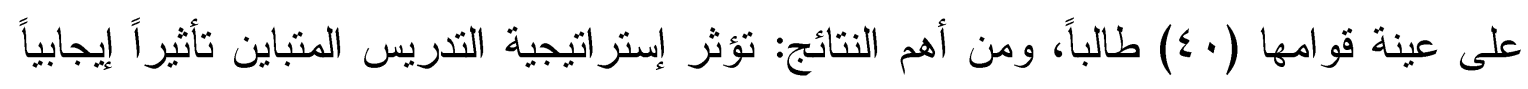
على أداء الطالب فى الأنشطة البدنية. 
إستخدم الباحث المنهج التجريبي بإستخدام التصميم التجريبى ذو القياس القبلى و البعدى لمجموعة

تجريبية و احدة وذلك لملاعمته لطبيعة البحث.

مجتمع وعينة (البحث:

يتكون مجتمع البحث من لاعبي كرة القدم بنادى الثباب الكويتى وتم اختيار عينة البحث بالطريقة العمدية دن لاعبى كرة القدم بنادى الثباب، وذلك لعدد (Yo) لاعب، وبلغت العينة الاستطلاعية عدد ( • (1) لاعبين وبنسبة مئوية مقدرها ( • (\%)، وبلغت العينة الأساسية عدد (0 (1) لاعب كمجموعة تجريبية و احدة وبنسبة مئوية مقدر ها ( • ع). أدوات ووسائل جمع البياتات: - الأدوات والأجهزة المستخدمة بالبحث:

قام الباحث بإستخدام الأدوات والأجهزة المناسبة لإجر اعات عينة البحث. مرفق (1) - إختبار ات المتغيرات البانية والمهارية: قام الباحث بعمل بمسح مرجعي للمر اجع العلمية المتخصصة و الدراسات المرجعية لتحديد أهم المهار ات الأساسية اللازمة للاعبي كرة القدم والأختبار ات التى تقيس مستوى هذه المهار ات.

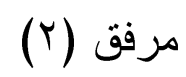

البرنامج التدريبي المقترح: من خلال المسح المرجعى للمر اجع العلمية المتخصصة وبعض الدراسات المرجعية أمكن للباحث التعرف على الأسس التى يمكن من خلالها تصميم البرنامج التدريبى المقترح بإستخدام التدريب المتباين.

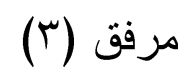
- تجانس عينة البحث:

تم إيجاد التجانس بين أفر اد مجتمع البحث فى بعض المتغيرات ومنها متغيرات النمو (السن الطول - الوزن)، العدر التدريبى وفى المتغير ات المهار ات الأساسية (ركل الكرة بالقدم اليمنى، ركل الكرة بالقدم اليسرى، الجرى بالكرة، تتطيط الكرة على الر أس، ضرب الكرة بالر أس على الحائط، ضرب الكرة بالر أس لمسافة، رمية التماس) لدى لاعبى كرة القدم بنادى الشباب، كما هو موضح فى جدول 
جدول (1)

تجانس عينة البحث (الأساسية - الاستطلاعية) فى متغيرات النمو والعمر التّريبى والمتغيرات

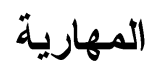

ro $=\dot{0}$

\begin{tabular}{|c|c|c|c|c|c|c|c|}
\hline الألكتواء & 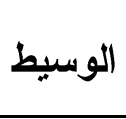 & الأنحر اف & المسابي & وحدة & المتغير ات & & a \\
\hline$\cdot, r \cdot \Lambda$ & $10, r_{0}$ & 1,90 & $10, \leq 0$ & سنة & 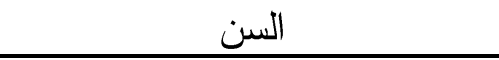 & \multirow{3}{*}{ 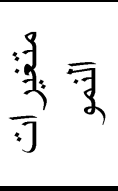 } & \multirow{3}{*}{1} \\
\hline$\cdot, r \varepsilon-$ & 177 & $0,9 V$ & 170,r & 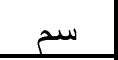 & الطول & & \\
\hline$\cdot, \wedge 9 \%-$ & $T \varepsilon$ & $r, 99$ & 74,11 & كجم - ام & 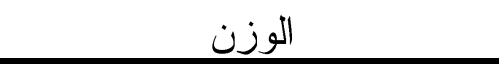 & & \\
\hline$\cdot, \varepsilon \leqslant 7$ & 1. & 1,10 & $1 \cdot, Y_{7}$ & سنة & \multicolumn{2}{|l|}{ العمر التدريبى } & $r$ \\
\hline$\cdot, 01 \leqslant$ & $1, r$. & ru,TV & $1, r_{1}$ & 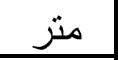 & ركل الكرة بالقدم اليمنى & \multirow{7}{*}{ 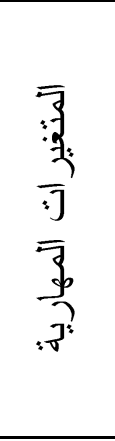 } & \multirow{7}{*}{ r } \\
\hline$\cdot, 110$ & $1, r_{0}$ & $r+, T I$ & $1, r 4$ & مثز & ركل الكرة بالقدم اليسرى & & \\
\hline $1, \leqslant \varepsilon$ & $\cdot, r$ & $1 \Lambda, \cdot r$ & $\cdot, \leqslant 0$ & ثانية & الجرى بالكرة & & \\
\hline $1, \wedge \varepsilon$ & $\cdot, \vee \vee$ & IY, YO & $\cdot, V \vee$ & مرة - مرة & تتطيط الكرة على الر أس & & \\
\hline$\cdot, \leqslant Y 0$ & $\cdot, V \cdot$ & $1 r, q$. & $\cdot, V \varepsilon$ & مثز & ضرب الكرة بالر أس على الحائط & & \\
\hline$\cdot, Y \wedge r-$ & $\cdot, 90$ & $1 \cdot, 79$ & $\cdot, 91$ & 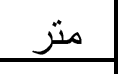 & ضرب الكرة بالر أس لمسافة & & \\
\hline$\cdot, 1 \mathrm{H}$ & $\cdot, \mathrm{V} r$ & 14,99 & $\cdot, V V$ & مثز & رمية التماس & & \\
\hline
\end{tabular}

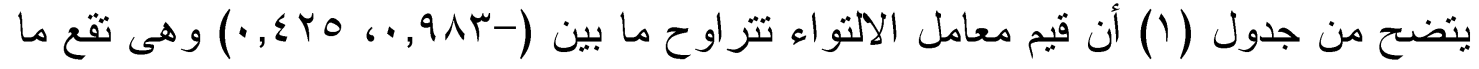

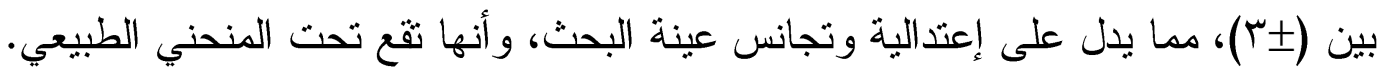
الار اسة الإستطلاعية:

قام الباحث بإجراء الدراسة الإسنطلاعية في الفترة من يوم 10/11/1 بrم إلى يوم • 10/11/ . ب و ذللك على عينة قو امها (0) لاعبين من مجتمع البحث ومن خار ج عينة البحث الأساسية. المعاملات العلمية للبحث: 
أستخدم الباحث صدق التمايز لأفر اد عينه البحث الأستطلاعية بين المجموعة المميزة و عددها (0) لاعبين وخارج العينة الأساسية للبحث، و المجموعة غير المميزة و عددها (0) لاعبين، كما

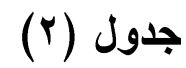

دلامة الفروق بين المجموعة المميزة والمجموعة غير المميزة فى الإختبار ات المهارية للاعبى كرة القدم

$0=r_{\dot{0}}=10$

\begin{tabular}{|c|c|c|c|c|c|c|c|}
\hline \multirow{2}{*}{ قيمة "تات } & \multicolumn{2}{|c|}{ مجموعة غير مميزة } & \multicolumn{2}{|c|}{ مجموعة مميزة } & \multirow{2}{*}{ وحدة القياس } & \multirow{2}{*}{ المتغير ات } & \multirow{2}{*}{ r } \\
\hline & $\varepsilon \pm$ & س & $\varepsilon \pm$ & س - ق & & & \\
\hline $7,9 \leq$ & $\cdot, 77$ & rT,T & $\cdot, \leqslant 0$ & 19,17 & 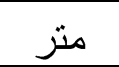 & ركل الكرة بالقدم اليمنى & 1 \\
\hline$\varepsilon, \cdot 9$ & 1,11 & Y I, T乏 & $1, Y_{7}$ & Y I,,$\vee q$ & 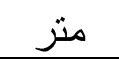 & ركل الكرة بالقدم اليسرى & r \\
\hline r o & $\cdot, 49$ & $11,7 \varepsilon$ & $\cdot, \wedge \wedge$ & 19,77 & ثانية & الجرى بالكرة & r \\
\hline$\varepsilon, 1 V$ & $\cdot, Y_{1}$ & $11,1 \mathrm{~V}$ & $\cdot, 71$ & $1 \cdot, r r$ & 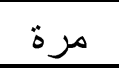 & تنطبط الكرة على الر أس & $\varepsilon$ \\
\hline$\varepsilon, \cdot \Lambda$ & ( & $\mid r, \varepsilon$. & $\cdot, \wedge \varepsilon$ & $11, r \leq$ & مثز & ضرب الكرة بالر أس على الحائط & 0 \\
\hline$r, 00$ & $\cdot, 01$ & $1 \cdot, \cdot 7$ & $\cdot, 0$ & $9, r V$ & 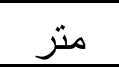 & ضرب الكرة بالر أس لمسافة & 7 \\
\hline r, $\leqslant 0$ & $\cdot, 79$ & $1 r, 7$. & $\cdot, \wedge 9$ & IY,rV & مثز & رمية التماس & V \\
\hline
\end{tabular}

يتضح من جدول (Y) المتوسط الحسابي والانحراف المعياري وقيمة (ت) المحسوبة بين المجمو عة المميزة و المجموعة غير المميزة في الاختبار ات المهارية، وهى أكبر من قيمة (ت) الجدولية، حيث يتضح وجود فروق دالة احصائياً بين المجموعة المميزة والمجموعة الغير المميزة في جميع الاختبارات المهارية لصالح المجموعة المميزة الأمر الذي يشير إلي صدق الاختبار ات فيما وضعت 
نم حساب ثبات الاختبار بطريقة إعادة نطبيق الاختبار مرة أخرى، وذلك لإيجاد قيمة معامل

الإرثباط بين النطبيق الأول والثاني، ونم التطبيق على المجموعة المميزة وعددها (ه) لاعبين وخارج العينة الأساسية للبحث بفارق زمني أسبوع عن التطبيق الأول، حيث طبقت نفس وله الاختبار ات وبنفس الأدوات و الظروف، ويتضح ذلك كما فى جدول (r).

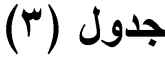

معامل الأرتباط (الثبات) بين التطبيقين الاول و الثانى في الأختبارات المهارية للاعبى كرة القدم $\dot{0}=\dot{0}$

\begin{tabular}{|c|c|c|c|c|c|c|c|}
\hline \multirow{2}{*}{ الإرتباط } & \multicolumn{2}{|c|}{ التطبيق الثاني } & \multicolumn{2}{|c|}{ التطبيق الأول } & \multirow{2}{*}{ القياس } & \multirow{2}{*}{ المتغيرات } & \\
\hline & $\varepsilon \pm$ & س & $\varepsilon \pm$ & س & & & \\
\hline $7,9 \leqslant$ & ד4 & rT,T & $\cdot, \varepsilon_{0}$ & $r 9,17$ & متز & ركل الكرة بالقدم البمنى & 1 \\
\hline$\varepsilon, .9$ & 1,11 & $Y, T \leqslant$ & 1,14 & r $1, v q$ & منز & ركل الكرة بالقدم اليسرى & r \\
\hline r, ro & . rq & $1 \Lambda, 7 \leqslant$ & $\cdot, \lambda \wedge$ & 19,74 & ثانية & الجرى بالكرة & r \\
\hline$\varepsilon, 1 \mathrm{~V}$ & $\cdot, r_{1}$ & $11,1 \mathrm{~V}$ & $\cdot, 71$ & $1 \cdot, \mu_{T}$ & مرة & تتطيط الكرة على الر أس & $\varepsilon$ \\
\hline$\varepsilon, \cdot \Lambda$ & ת ז & $\mid r, \varepsilon$. & $\cdot, \lambda \varepsilon$ & $11, r \varepsilon$ & مثز & ضرب الكرة بالر أس على الحائط & 0 \\
\hline$r, 00$ & $\cdot, 01$ & $1 \cdot, \cdot 7$ & $\cdot, 0$. & $9, \mathrm{rV}$ & مثز & ضرب الكرة بالر أس لمسافة & 7 \\
\hline$r, \Sigma 0$ & $\cdot, 79$ & $1 r, 7$. & $\cdot, \wedge 9$ & Ir,rv & 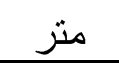 & رمية التماس & $\mathrm{v}$ \\
\hline
\end{tabular}

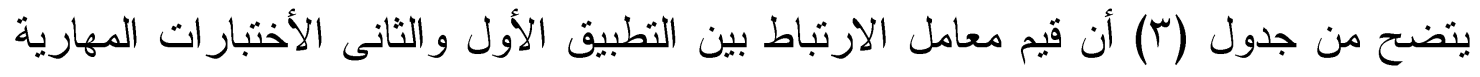

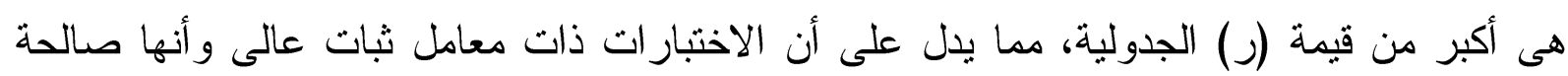

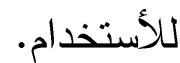

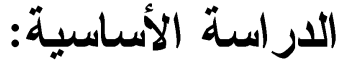

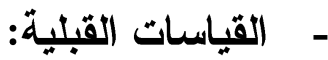




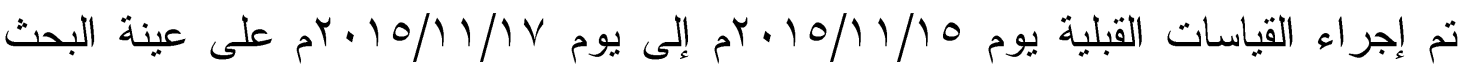
الأساسية وذلك في المهار ات الأساسية لكرة القدم قبد البحث.

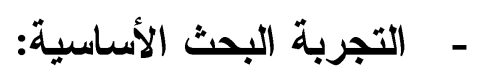

تم تطبيق البرنامج المقترح باستخدام بأسلوب التدريب المتباين على عدد (0 (1) لاعب كرة القدم من نادى الثباب الكويتى وهم مجموعة البحث التجريبية، لمدة (Y () أسبوع بعدد (TY) وحدة تدريبية، و عدد الوحدات خلال الأسبوع (r) وحدات تدريبية، زمن الوحدة التدريبية اليومية ( و (9) دقيقة فى الفترة

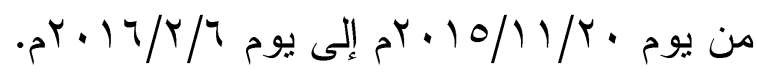
-

بعد تطبيق البرنامج التدريبى المقترح بأسلوب التدريب المتباين على عينة البحث التجريبية، قام الباحث بالقياس البعدى للأختبار ات المهارية يوم T/Y/9 1 • بم. المعالجات الإحصائية: قام الباحث بإستخدم حزمة البرنامج الإحصائى للعلوم الإجتماعية (spss) بإستخدام الحاسب الآلى فى المعالجات الإحصائية وهى (المتوسط الحسابى - الوسيط - الانحر اف المعيارى - معامل الالتو اء - معامل الارتباط - النسبة المئوية - اختبار "ت" - نسب التحسن).

عرض ومناقشة النتائج:

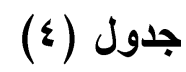

دلامة الفروق بين القياسين القبلى والبعدى لمجموعة البحث التجريبية فى مستوى الأداء المهارى للاعبي كرة القدم

$10=0$

\begin{tabular}{|c|c|c|c|c|c|c|c|}
\hline \multirow{2}{*}{ قالمحسوبة "ت } & \multicolumn{2}{|c|}{ القياس البعدي } & \multicolumn{2}{|c|}{ القياس القبلي } & \multirow{2}{*}{ ولقياس } & \multirow{2}{*}{ المتغير ات } & \multirow{2}{*}{ b } \\
\hline & $\varepsilon \pm$ & س - س & $\varepsilon \pm$ & س - س & & & \\
\hline$* \varepsilon, 7$ & $1, \cdot r$ & 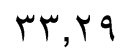 & $1, r_{1}$ & r T, TV & مثر & ركل الكرة بالقدم البمني & 1 \\
\hline$* Y, Y \leq$ & 1,10 & $r \leqslant, V T$ & $1,1,4$ & $r(T, Y$ & 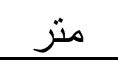 & ركل الكرة بالقدم البسرى & r \\
\hline$* Y, \leq 0$ & $\cdot, \varepsilon r$ & $1 \wedge, Y \leqslant$ & $\cdot, \leqslant 0$ & $1 \Lambda, \cdot r$ & ثانية & الجرى بالكرة & r \\
\hline$* 1, \wedge \vee$ & $\cdot, V Y$ & $M, Y Y$ & $\cdot, \mathrm{VV}$ & $I Y, Y \leqslant$ & 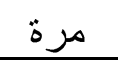 & تتطيط الكرة على الر أس & $\varepsilon$ \\
\hline$* Y, 9 \uparrow$ & $\cdot, \vee \vee 9$ & $1 T, 1 \leq$ & $\cdot, \vee \vee \leqslant$ & $1, r, q$. & 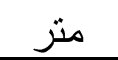 & ضرب الكرة بالر أس على الحائط & 0 \\
\hline$* \varepsilon, 19$ & $\cdot, \wedge \varepsilon$ & $1 \cdot, \leqslant Y$ & $\cdot, 9 \wedge$ & $1 \cdot, 79$ & 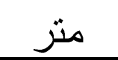 & ضرب الكرة بالر أس لمسافة & Y \\
\hline
\end{tabular}




\begin{tabular}{|c|c|c|c|c|c|c|c|c|}
\hline \multicolumn{3}{|c|}{ ISSN : YVYO-\{רIX } & \multicolumn{2}{|c|}{ 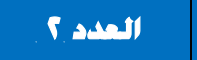 } & \multicolumn{2}{|c|}{ الههبلة العلهية لعلوم الرياضة } & \multicolumn{2}{|c|}{ 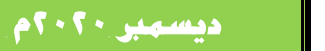 } \\
\hline$* \varepsilon, 1 \Gamma$ & $\cdot, \wedge 7$ & $1 \varepsilon$, & & $\cdot, \mathrm{V}$ & $1 \%, 70$ & متر & رمبة & $\mathrm{v}$ \\
\hline
\end{tabular}

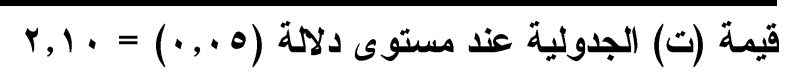

يتضح من جدول (§) وجود فروق ذات دلالة إحصائية بين القياسين القبلى و البعدى لمجموعة البحث

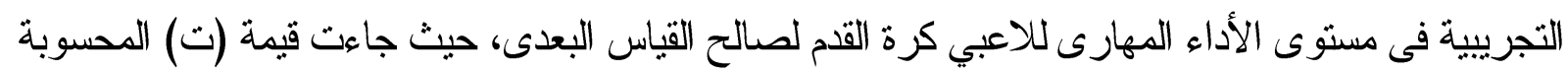
أكبر من قيمة (ت) الجدولية.

جدول (0)

نسب التحسن بين القياسين القبلى والبعدى لمجموعة البحث التجريبية فى مستوى الأداء المهارى للاعبي كرة القدام

$10=0$

\begin{tabular}{|c|c|c|c|c|c|c|c|}
\hline \multirow{2}{*}{ التحسبة } & \multicolumn{2}{|c|}{ القياس البعدي } & \multicolumn{2}{|c|}{ القياس القبلي } & \multirow{2}{*}{ والقياس } & \multirow{2}{*}{ المتغيرات } & \multirow{2}{*}{ م } \\
\hline & $\varepsilon \pm$ & س - س & $\varepsilon \pm$ & س - ن & & & \\
\hline$\%, r, 1 \wedge$ & $1, \cdot r$ & r r, & $1, r$, & YT,TV & مثز & ركل الكرة بالقدم اليمنى & 1 \\
\hline$\% \wedge \wedge, \leqslant \vee$ & 1,10 & $Y \leq, V \uparrow$ & 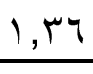 & $r(T, 7)$ & 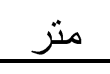 & ركل الكرة بالقدم اليسرى & r \\
\hline$\% 1 r, 10$ & $\cdot, \varepsilon \Gamma$ & $1 \Lambda, Y \varepsilon$ & $\cdot, \leqslant 0$ & $1 \Lambda, \cdot r$ & ثانية & الجرى بالكرة & $r$ \\
\hline$\% 1, r, 4$ & $\cdot, \mathrm{VT}$ & IY,YY & $\cdot, \mathrm{VV}$ & $1 Y, Y \Sigma$ & مرة & تتطبط الكرة على الر أس & $\varepsilon$ \\
\hline$\% 19, \wedge$. & $\cdot, \vee \vee 9$ & $1 r, 1 \leq$ & $\cdot, V \leqslant$ & $1 \%, q$. & 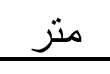 & ضرب الكرة بالر أس على الحائط & - \\
\hline $11, \leqslant r$ & $\cdot, \wedge \varepsilon$ & $1 \cdot, \varepsilon Y$ & $\cdot, 9 \Lambda$ & $1 \cdot, 79$ & مثز & ضرب الكرة بالر أس لمسافة & 1 \\
\hline$\% \curlyvee \varepsilon, T \vee$ & $\cdot, \wedge 4$ & $1 \Sigma, \mu \mu$ & $\cdot, v_{1}$ & 14,70 & مثز & رمية التماس & $\mathrm{v}$ \\
\hline
\end{tabular}

يتضح من جدول (0) نسب التحسن بين القياسين القبلى و البعدى لمجموعة البحث التجريبية فى لهى مستوى الأداء المهارى للمتغير ات المهارية للاعبي كرة القدم لصالح القياس البعدى.

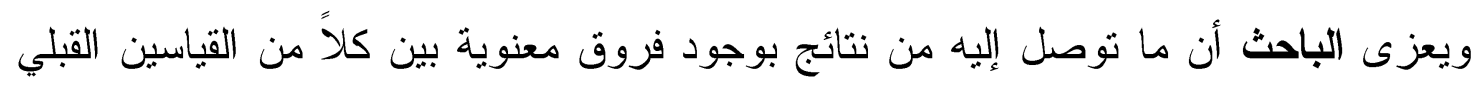
و البعدي لهجموعة البحث التجريبية فى مستوى الأداء المهارى للمتغيرات المهارية للاعبي كرة القدم لصالح القياس البعدى يدل على أن البرنامج المقترح باستخدام أسلوب التدريب المتباين و الخلط و المزج

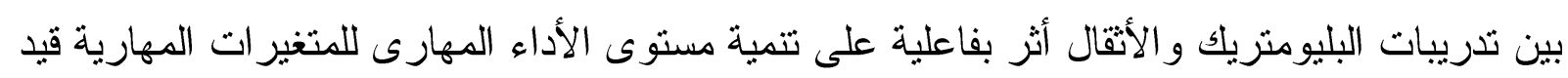
البحث. ويشير الباحث أن التخطيط الجيد لعملية التدريب الرياضى بالنسبة للاعبين تساهم مساهمة فعالة فى التتمية والأرثقاء والتحسن لمستوى الأداء الرياضى عند أستخدام وسائل وطرق تدريبية حديثة 
ومتطورة وربما تكون مدمجة بأكثر من أسلوب تدريبى مثل التدريب المتباين الذى يدمج بين كلاً من

$$
\text { (التدريب بالأثقال + التدريب بالبليومترك). }
$$

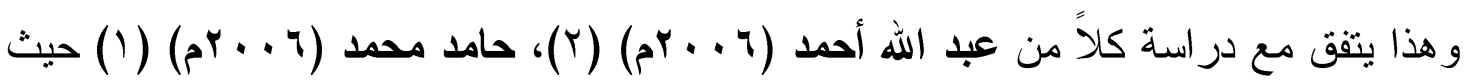
أوضحت نتائج الدراسات أن تخطيط التدريب عبارة عن الإجراءات الضرورية المحددة والمدونة التي يضعها المدرب، ويلتزم بها لتتمية وتظوير حالة التدريب عند اللاعب و الفريق للوصول الي أحسن مستوى من الأداء أثناء المباريات، وكلما تميز المدرب الرياضى بالتأهيل التخصصى و إتقانة للمعارف

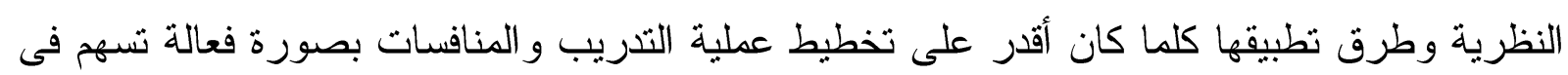
تطوير وتتمية المستوى الرياضى و اللاعبين ككل.

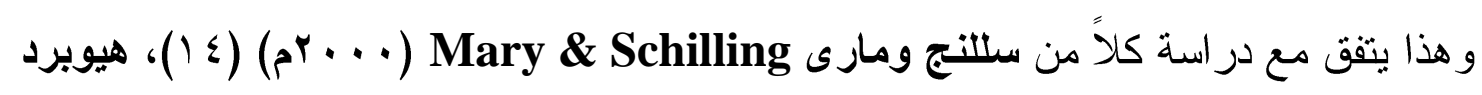
دانيال Hubbard Daniel (9 . . . rم) (r ( ) حيث أكدت نتائج الدر اسات على فاعلية التمرينات المركبة في تطوير نركيز الانتباه وبعض المهار ات الحركية في الأنشطة الرياضية وتطوير مستوى الأداء المهارى للمهار ات الحركية المنفردة و المركبة فى الأنشطة الرياضية المختلفة.

الإستنتاجات و التوصيات:

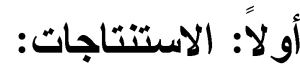

ا-نوجد فروق ذات دلالة إحصائية بين القياسين القبلى و البعدى للمجموعة التجريبية فى مستوى الأداء المهارى لصالح القياس البعدى للاعبي كرة القدم نتيجة تأثثر البرنامج التدريبى المقترح باستخدام

$$
\text { أسلوب الندريب المنباين. }
$$

r- البرنامج المقترح باستخدام أسلوب الندريب المتباين والخلط والمزج بين تدريبات البليومتريك والأثقال أثر بفاعلية في تتمية وتحسين مستوى المهارى لاى لاعبى كرة القدم. ثانياً: التوصيات:

1- مر اعاة تطبيق بر امج التدريب المتباين بالخلط و المزج بين تدريبات البليومنريك و الأتقال لدى لاعبى كرة القدم لما لها من مساهمة وفاعلية فى تحسين وتطوير الأداء المهارى.

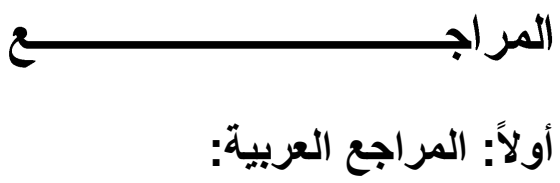


: "ثأثثر إسـتخدام الأسـلوب المتباين على مسـتوى

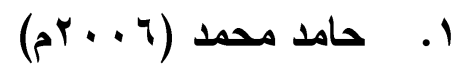

التحصـــيل الحركى و المعرفى لبعض المهار ات

الأســــــــــة في كرة لليد"، مجلة علوم وفنون

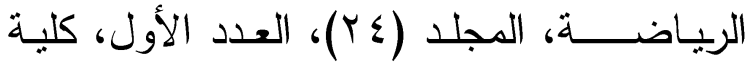

التربية الرياضية بنات، جامعة حلوان.

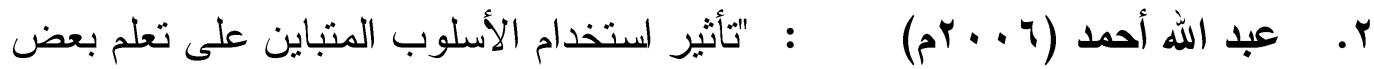

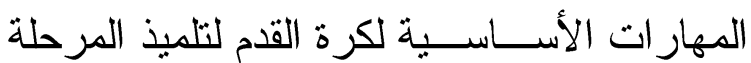
الإعدادية"، رســــللة مـاجســتير، كليـة التزبية

الرياضية، جامعة المنصورة.

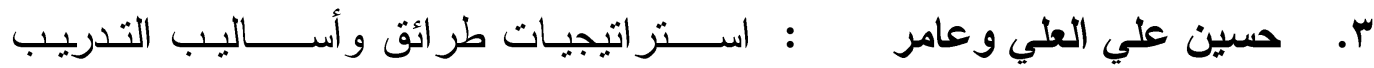

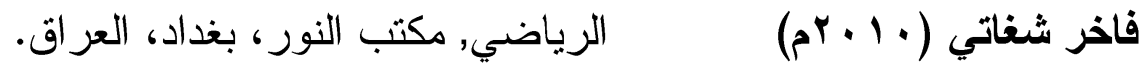
: تأثير التدريب المتباين في تطوير قوة عضــلات الرجلين للاعبي كرة الســلـة، مجلة كلية التربية ونوفل قحطان محمد ومناف

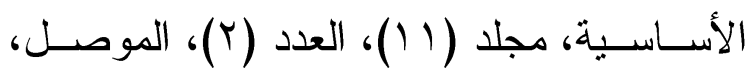
ماجد حسن (11) ملتوم) العراق

ه. عبد العزيز النمر و ناريمان التدريب الرياضي (تدريب الأثقال وتصميم برامج القوة وتخطيط الموسم التذريبي)، للقاهرة، مركز الخطيب (997) (199) الكتاب للنشر

: تأثير استخدام بعض الأساليب الفسيولوجية لتقنين 7. . عصام عبد الحميد حمل التدريب على كفاءة الجهاز الدوري التتفسي $(a r \cdots)$ وبعض المتغير ات البدنية و المهارية لدى ناشـــئ

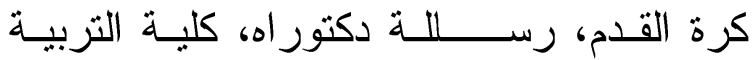
الرياضية، جامعة المنيا. طرق و أسـاليب التدريب لتنمية وتطوير القدر ات V. على فهمي البيك وعماد اللاهو ائية و الهو ائية، منشأة المعارف، مصر . الدين عباس ومحمد أحمد

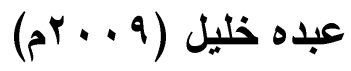


: تأثير تندريبات الأثقال و البليومنرك على بعض

^. مروان على عبد الله

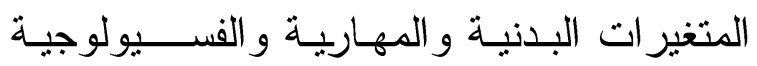

$$
(a r \cdot r)
$$

للاعبي كرة اليد، رســـالة دكتور اه، كلية التربية

الرياضبة، جامعة المنيا.

ثنانياً: المراجع الإجليزية:

9. Brad McGregor : the application of complex training for $(Y \cdot T)$ the development of explosive power, Journal of Strength and Conditioning Research, I $\leqslant(\Gamma)$, pp: $\longleftarrow$.

1. Chip Sigmon ( $r \ldots r)$ : or-week Basketball Training, Human Kinetics.

11. Duthie, G.M., Young, : The acute effects of heavy loads on W.B. and Aitken, D.A. $(r \ldots r)$ jump squat performance: an evaluation of the complex and contrast methods of power development, Journal of Strength and Conditioning Research, $17(\Sigma)$ pp: or._or^.

Ir. Fletcher, I.M., and : Effect of an $\Lambda_{-W e e k}$ Combined M. Hartwell $(r \ldots \varepsilon)$

Weights and Plyometrics Training Program on Golf Drive Performance, The Journal of Strength and Conditioning Research, Vol. '^, No. ', pp. $09-7 r$.

1\%. Hubbard, Daniel. : The Impact of Different Tiered $(r \cdot q)$ Instruction for physical activities Learners at the secondary level with a Focus on Gender, unpublished PhD thesis, California State Unifersty.

1\&. Schilling \& Mary : The effect of three Styles for of $(r \cdot \cdots)$ teaching on University Students Sports Performance. htt: // ericirsyedu / Pluels. Cgi.

10. Smilios Ilias, : Short-term effects of selected exercise Theophilos Pilianidis, and load in contrast training on vertical Konstantinos

Sotiropoulos, jump performance, J Strength Cond Res. Y..० Feb ; 19 (1): Greece.

Manolis Antonakis, 


\begin{tabular}{|c|c|c|c|}
\hline ISSN : YVYO-¿TIX & | الصدد r & الهبملة الملهية لملىم الريلغة & ديm \\
\hline
\end{tabular}

Savvas P Tokmakidis

$(Y \cdots \theta)$ 